\title{
A systematic review of health service interventions to reduce use of unplanned health care in rural areas
}

\begin{abstract}
\section{Rationale and Objective}

Use of unplanned health care has long been increasing, and not enough is known about which interventions may reduce use. We aimed to review the effectiveness of interventions to reduce the use of unplanned health care by rural populations.

\section{Methods}

Systematic review. Scientific databases (Medline, Embase and Central), grey literature and selected references were searched. Study quality and bias was assessed using Cochrane Risk of Bias and modified Newcastle Ottawa Scales. Results were summarised narratively.

\section{Results}

2708 scientific articles, reports and other documents were found. After screening, 33 studies met the eligibility criteria, of which eight were randomised controlled trials, thirteen were observational studies of unplanned care use before and after new practices were implemented, and twelve compared intervention patients with non-randomised control patients. Eight of the 33 studies reported modest statistically significant reductions in unplanned emergency care use while two reported statistically significant increases in unplanned care. Reductions were associated with preventative medicine, telemedicine and targeting chronic illnesses. Costsavings were also reported for some interventions.
\end{abstract}

\section{Conclusion}

Relatively few studies report on unscheduled medical care by specifically rural populations, and interventions were associated with modest reductions in unplanned care use. Future research should evaluate interventions more robustly and more clearly report the results. 


\section{Introduction}

The use of emergency and unplanned care in developed countries has long been increasing [13]. For instance, emergency hospital admissions in England rose by $32 \%$ over 14 years, from 4 million/year in 1998/99 [4] to 5.3 million in 2012/13 [5]. From 2001/02 to 2012/13 there was a $26 \%$ increase in emergency hospital admissions for potentially avoidable conditions such as ear or urinary tract infections [5]. The annual total number of emergency calls to English ambulance services rose from 5.6 million in 2004/05 [6] to 9.08 million in 2012/13 [7], a 62\% growth over eight years. The causes of these rises are contentious, with interest concentrated on 'inappropriate' attendances [8-10] and whether changes in provision of primary care may be spurring demand for unplanned care [2,11,12]. Ageing populations in many countries $[2,13,14]$ are expected to impose still greater burdens on the urgent care system in the future.

\section{Rural Health}

Compared to urban populations, health outcomes in rural communities in developed countries are affected by longer travel distances using less well-maintained infrastructure [15], less exposure to and participation in disease prevention programs [16], delayed disease diagnosis [17], confusion about access to urgent care [18,19], reduced choice of providers and treatment plans [16,20-23], and less support for people managing chronic illness and their carers [15,16,24-26]. Rural residents may have higher costs of living and limited employment opportunities in some areas, but undoubtedly some costs in rural areas are likely to be less than they are for urban communities. Rural populations tend to relatively economically deprived and health-disadvantaged compared to urban groups in the USA [27] or Australia [28], but within Europe, rural communities tend to be more affluent on average with reduced uptake of government benefits [29]. This has led to concerns within Europe that overall affluence can hide poverty $[30,31]$ and ill health in vulnerable rural individuals $[32,33]$.

\section{Objectives of this review}

This review aimed to determine which, if any, health service interventions reduce use of unplanned health care by rural populations. Previous reviews [9,34] considered which interventions were most successful at reducing use of unplanned care by the whole population 
(combined urban and rural), but interventions addressing only rural residents have not been previously studied. We defined "unplanned" use of health care to include all care sought without advance appointments, such as visits to hospital emergency departments, unscheduled hospital admissions, drop-in clinic visits, emergency transport or mobile medical staff call outs and use of out-of-hour GP services. This wide perspective is especially important in the context of British health care provision. The National Health Service in the UK is a taxpayer-funded universal health service that provides the vast majority of health care [35], including multiple forms of unscheduled care such as emergency departments, emergency transport by ambulance, out-of-hours appointments and unplanned home visits. From the perspective of NHS provision, reductions in any form of unplanned health care use are potentially beneficial and there are net system gains if more expensive forms of unscheduled health care can be reduced, even if as a consequence, demand for other types of unplanned care may rise.

\section{Methods}

\section{Protocol}

The review protocol was registered with the PROSPERO International prospective register of systematic reviews at the University of York in July 2014 (ref. no. = CRD42014010508). Search terms were developed and tested using the Medline and Embase archives and undertaken in three scientific databases from 1984 to April 2014 (MEDline, Embase and Central) and in 22 grey literature sources. References of background policy documents and eligible studies were screened to check for further articles to include.

"Remote" was treated as a synonym for rural only when it denoted locations away from urban development, and not just physically removed from the care provider. The intervention had to be provided by health services (qualified health professionals), which meant that initiatives such as road speed limits or safety regulations in the workplace were excluded. No restrictions were placed on study design, patient characteristics or language. Studies were restricted to populations living in OECD member nations to ensure comparability of health service provision. We use the terms urgent, unscheduled and unplanned as applied by the original researchers and otherwise as interchangeable.

\section{Study Eligibility and Quality Assessment}


Included studies had to feature all of these aspects:

1) Rurality (rural or remote);

2) Mention of an event (admission, incident, appointment, episode, care provided, treatment, assessment etc.)

3) Urgent adjective for the event (unscheduled, urgent, unplanned or emergency)

4) Intervention plan or practices (with measured impact on demand for urgent care)

5) Study design that indicated comparators, such as randomized controlled trial, case series, case controls, etc.

One researcher initially screened all scientific articles for inclusion criteria, with a $20 \%$ sample verified by a second researcher for consistency; initial agreement between screeners was $93.7 \%$ and disagreements were resolved by discussion. Reference lists of review and policy documents identified from grey literature that had passed through initial screening were then checked for further articles that might meet our inclusion criteria. Standard format tables were used for data extraction. These described baseline characteristics, study outcomes, risk of bias and study quality which were generated, initially by one researcher and verified by a second author, with differences resolved by discussion. Risk of bias assessment was undertaken using Cochrane criteria [36] for randomised controlled trials and a modified Newcastle-Ottawa Scale [37] for other studies. Heterogeneity of interventions and study design meant that meta-analysis was not possible, so a narrative analysis was undertaken.

Figure 1. PRISMA Diagram of Search and Study Selection Procedure

\section{Results}

The search process is illustrated in Figure 1. 1418 unique scientific articles were found, plus 1290 (sometimes duplicated) reports and other documents from grey literature. Full search operations and results are reported in supplemental tables S1-S2 for scientific literature and S3 for grey literature. 27 scientific articles were included from the scientific literature search and five reports came from grey literature. One item [38] was found from screening references of other reviews on unplanned care use. Therefore a total of 33 articles were included. All final 
selected articles were written in English as no other language articles met the inclusion criteria. Studies were undertaken in the USA, Australia, UK, Canada, Japan and Germany. Over 70\% of studies monitored for possible change in demand for at least 12 months either after or concurrent with the intervention. Participant groups tended to be large (dozens or even hundreds of consultations or treatment opportunities).

\section{Table 1 about here}

\section{Study characteristics}

All selected papers mentioned use of unplanned care as an outcome measure. The most common outcomes were visits to accident \& emergency departments $(\mathrm{n}=10)$ and unscheduled hospital admissions ( $\mathrm{n}=14$; Table 1$)$. Most studies featured patients of any age, six targeted children and seven were focused mostly or entirely on older adults.

There were 33 articles describing 31 research projects. Thaker et al. [39] and Sabesan and Brennan [40] gave similar results from the same Australian telemedicine program at different points in time, while conclusions were available from two sources about the same "virtual wards" program in south western England [41,42]. All other included articles described unique projects.

\section{Risk of Bias}

High risk for performance bias was determined for a majority of RCTs, because it was apparent that participants would know which arm of the trial they were in. Risk of bias was often uncertain for randomisation procedures (selection bias), due to inadequate information supplied in the article (Supplemental Tables S4 and S5). Risk of bias ratings for studies only reported in conference abstracts tended to be unclear in all domains in spite of our efforts to contact the authors for further information, demonstrating how difficult it can be to find useful information in such brief reports for the purposes of a systematic review. The equivalent forms of bias (Newcastle Ottawa Scale indicators) for non-RCTs were less likely to be high or unclear. Among non-RCTs, high bias was most likely to result from how comparison groups were treated and there was some indication (high risk) of incomplete data reporting. 


\section{Study Design}

Eight RCTs were included in the review while 25 non-RCTs either monitored possible changes in unscheduled care use before or after new practices were implemented, or between an intervention group and matched non-randomised controls. Eight studies (one RCT [55] and seven non-RCT design) reported statistically significant reductions in unplanned care use. Table 2 lists these studies with their clinical impacts. Four of the non-RCTs reported no statistically significant reductions in unplanned care use. The remaining 14 non-RCTs mostly focused on pragmatic aspects of pilot studies and although they usually reported reductions in unplanned care use, they did not comment on possible statistical significance.

\section{Health conditions and strategies employed to reduce use}

Intervention strategies were diverse although similar elements were often in both the most and least successful interventions. In the following discussion interventions were categorised as self-management and case-management, specific conditions, telemedicine (including remote support by specialists of local health care professionals), acute presentations and other. Some studies fall into more than one of these categories.

\section{Self-management and case-management}

Twelve papers described programs that teach patients how to better self-manage long-term illness, which included diabetes [43], heart failure [44-46], COPD [47], mental illness [48-50], and asthma [51-54]. In one of the heart failure studies [44, an RCT], patients had statistically significant increased numbers $(\mathrm{p}=0.01)$ of unscheduled medical appointments, possibly due to increased patient anxiety about signs of deterioration in an intense case management scheme. In two of these self-management studies (on COPD [47] and asthma [52]) there was statistically significant reduced use of unscheduled care $(\mathrm{p}<0.05)$. The other nine papers did not report statistically significant results about changes in usage of unplanned care.

Six papers were concerned with optimal case management of and routine treatment for chronically ill ("high risk") individuals in the community [41,42,55-58]. One of these was the only RCT included in the review that reported statistically significant reduced use of emergency care [58], but it also had high or unclear risk of bias in all domains (Supplemental Table S4). The other 5 showed no significant reductions. The 'Virtual Wards' project in 
England also illustrates contrasting views on the same programme. The Kings Fund [55] reported an impressive $\sim 20 \%$ reduction in emergency admissions from patients in the highest risk groups (before and after intervention was implemented). Yet, comparison was made with high risk patients not part of the Virtual Wards programme and their admission rate was not statistically different from the intervention group. In a more detailed analysis of the same intervention over a longer period and using nationally matched case controls, the Nuffield Trust [41] concluded that the intervention group did not have significantly fewer visits to A\&E and that overall, the Virtual Wards project was not highly cost effective compared to usual care.

\section{Specific conditions}

Two studies addressed cancer treatment [39,40,59], reporting how routine monitoring or treatment in the community might prevent use of emergency medical care, but did not achieve significant decreases in usage of unscheduled care Three reports described management of other specific risks or problems: attempted suicide [60; significant reductions in usage achieved], acute burns [61, achieved significant reductions in emergency transport] and complications after discharge from hospital [62, reductions in usage not significant]. Four studies [38,63-65] described interventions that addressed unscheduled treatment needed for unspecified conditions of any severity; only one of these [38], which described provision of low cost walk-in clinics, led to a significant reduction in usage of unscheduled care. One article addressed major trauma [66; significant reduction achieved] while two articles $[67,68]$ focused on relatively minor or potentially self-limiting problems such as burns, eye infections, cystitis and other ambulatory conditions (neither achieved significant reductions in usage of unscheduled care). Two studies [38,64] reported on changes in unplanned care use associated with alternative types of service provision (such as walk-in centres, ad-hoc telephone consultations and community clinics), with no significant fall seen in the UK [64] but a significant decrease in unplanned care use in the USA [38].

\section{Telemedicine}

Thirteen articles [39,40,45,46,48,49,59,61,65-69] described telemedicine interventions. One telemedicine service offered for routine care was unexpectedly utilised for urgent presentations $[39,40]$ and observed to reduce emergency transfer and hospitalisation. In three projects $[46,59,69]$ it was hoped that technology used to remotely monitor chronic conditions in 
individual cases would lead to less usage of unplanned care, but results were mixed. Technology reduced unscheduled hospital visits in a group of children on home-ventilators ( $\mathrm{p}$ $<0.05$ ) [69], without significant increases in other urgent care measures. Combined total scheduled and unscheduled clinic visits were reduced significantly $(\mathrm{p}<0.001)$ while unscheduled visits significantly increased $(\mathrm{p}=0.009)$ in a heart failure application of telemedicine [46]. A third study [59], employing tele-monitoring and tele-prompting of American military veterans with cancer, reported more visits to emergency departments in the intervention over control group (p-values not available).

\section{Acute presentations}

Three projects $[49,63,67]$ implemented triage protocols to assess immediate medical needs (or lack thereof) from unplanned presentations, and patients were often referred to other providers. No statistically significant reductions were found. Seven studies $[48,49,61,65-68]$ enabled immediate local assessment and treatment by staff who were not specialists in emergency care but acting under the guidance of suitably qualified but remotely located emergency experts. Statistically significant reductions in use of unscheduled care were achieved in only two $[61,66]$ of these seven studies. In most of the telemedicine applications, unplanned care was still sought and received, but the costs for providing care were believed to be lower than an alternative protocol of transport to, assessment at and treatment at a large hospital emergency department.

\section{Other: concern to not increase usage}

Two articles describe interventions that were not so much intended to reduce unscheduled care but rather were concerned not to increase it $[56,70]$. These papers assessed the safety and reliability of treatment or care by non-expert staff which normally would have provided by a more qualified professional. The outcome measures were whether emergency presentation, incorrect diagnosis or treatment or follow-up presentation for the same condition was more likely depending on whether original diagnosis or treatment was made by a health care assistant, non-emergency specialist (general practitioner), remotely located emergency specialists or onsite emergency-specialists. Both studies found no evidence of increased urgent treatment after care by any type of professional. 


\section{Benefits besides reduced use of urgent care}

In most of the telemedicine applications, unplanned care was still sought and received, but the costs for providing care were believed to be lower than an alternative protocol of transport to, assessment at, and treatment at a large hospital emergency department. Stated per patient estimated cost savings in preventing emergency transport or transfers were Canadian $\$ 300$ (US $\$ 326$ at August 2015 prices) [48], Canadian \$5350 (US \$5425) [65] and UK £929 (US \$2210.19) [67]. These cost-savings were calculated as the cost to transport plus cost to treat at emergency centre minus the cost to treat using telemedicine. Total savings in one multi-centre telemedicine project were calculated at Australian \$320,118 (US \$340,370) [39], although not every centre in the project had net savings. In the context of the Canadian, UK and Australian health systems, these savings per patient or per project were considered by the study authors to be substantial and justified continued service provision. Net cost savings were claimed but not specified in two studies [56,57], while some articles other reported valuable and usually statistically significant intervention benefits (at $p \leq 0.05)$ such as earlier warning of clinical decline [46], reduced number of scheduled clinic visits [46] or reduced days of bed care in hospital [59].

\section{Discussion}

There was little high quality research assessing interventions to reduce unplanned healthcare use by rural residents. Weak evidence from eight studies (one RCT and seven non-RCT design) showed statistically significant reductions in unplanned care use. Three of these articles were concerned with management of chronic illness (asthma, COPD and generic), three were telemedicine articles (respiratory failure, advice about burns treatment or suspected major trauma and reduction in suicide risk), and one described affordable price community health clinics that provided preventative care to an otherwise underserved population. The majority of the other 25 articles reported reductions in use of unplanned care which lacked statistical significance, which often wasn't tested for at all. Intervention elements and strategies were often similar across both statistically significant and non-significant articles making it difficult to identify which intervention strategies were most successful, although programs that promoted self-management of chronic illness, increased access to services and telemedicine often reduced use. Incomplete reporting was a problem among some of our included reports 
which were only available as conference proceedings (in spite of our efforts to find follow-up publications). More rigorous study designs (e.g. randomised controlled trials), more effort to make statistical comparisons, and more detailed evaluation of services that tend to be only described in conference proceedings would be desirable in future research.

Recurring problems with delivering rural health care that have been identified in other literature also surfaced in our review. For instance, in an education program for COPD in a small town (population $=5260)$ [47], it was noted that most participants came from within the town and not from the surrounding rural region, consistent with claims that rural residents tend to participate less often in health promotion programs [16]. Poor support networks for rural elders with chronic illness is often mentioned in commentaries on rural health [20,71-75], and was touched upon in our included studies [56,58]. Other obstacles were described, such as reluctance by emergency services staff to implement even a quite brief (and ultimately ineffective) preventative asthma intervention [51]. This reluctance by emergency staff to provide preventative education may be unfortunate in the rural context, because some rural groups (eg., agricultural workers) are very low users of primary care, so the only opportunity to promote preventative health management to these populations may be during their contact with emergency services [20,72-74]. More positive results were found in many telemedicine reports which cited an increase in treatment options for rural communities as an important benefit $[65,66]$ that redresses problems of limited treatment options and service provision in rural communities [20,71-74]. The review found no evidence that touched upon grossly inappropriate presentations or that implicated poor access to out-of-hours consultations with family doctors.

Our findings about which interventions work for rural populations are broadly in agreement with findings of other reviews of unscheduled medical care for combined urban and rural populations. Three relevant and recent systematic reviews considered interventions on combined urban and rural populations. Purdy et al [76] concluded that the following factors may reduce unplanned hospital admissions: preventative education, especially in selfmanagement, interventions that address heart failure, rehabilitation, telemedicine, exercise promotion, and continuity of care. Huntley et al [77] found that continuity of care interventions may reduce unplanned admissions. Ismail et al [9] concluded that walk-in centres, out-ofhours GP access and telephone triage in primary care had negligible impacts on demand for unscheduled care, but that emergency nurse practitioners in community primary care may 
reduce such demand. Our review, with a focus on usage by rural residents, finds no evidence to contradict the conclusions of these other reviews. It seems likely that most interventions suitable for urban populations will also be effective for rural communities.

\section{Limitations}

The inclusion of broad categories of unscheduled care use (not just attendances and presentations to the emergency department) is a strength of the review, but this wide definition also precluded assessment using meta-analysis. Some implemented interventions may never have been considered for publication and as a consequence their results cannot contribute to our review. We searched for under-evaluated and under-reported interventions in grey literature but found relatively few items. More studies should be rigorously reported and evaluated. Publication bias may also have impacted our findings.

We do not consider how the needs of health care needs or problems of rural populations may vary by country. Most of our studies came from North America, Japan or Australia where rural populations generally have lower socio-economic status and poorer health outcomes than urban communities. This is in contrast to the UK or Germany where rural populations are mostly more affluent than the national average. There were insufficient studies to draw strong conclusions, but there was no apparent difference in how well interventions worked whether the location was UK/Germany or USA/Japan/Australia. A more important difference rather than socio-economic status reversal, or even different formats of health service provision, may be the distances involved when telemedicine interventions are employed in each country. The USA and Australia are continental wide with potentially vast distances to cover when transport is required. The potential cost-savings from telemedicine in these locations are probably much higher than for Japan/Germany/UK. Conversely, the high density of population and health care facilities in the latter countries may reduce risks associated with experimental protocols to not immediately transport patients, because if it's decided that a visit to the emergency department is required after all, it's not too far to go. It is beyond the scope of this paper to assess the many possible risk balance trade-offs involved in such intervention planning.

The review only briefly discusses other types of desirable outcomes besides demand for unscheduled care. Our analysis determined risk of bias, and not many other indicators of study quality that have been suggested but are rarely reported in systematic reviews (a long if still not exhaustive list of candidate quality indicators is in Deeks et al 2003). 


\section{Conclusions}

Our review on rural residents broadly concurs with other reviews on combined urban-rural populations that targeting chronic illnesses management, telemedicine and community health clinics may be effective at reducing emergency presentations. It is useful to establish that interventions that work well in combined urban-rural populations seem to also be effective in the rural subgroup alone. Telemedicine was most consistently reported as effective at reducing unplanned care use or expensive emergency transport, particularly when it brought specialist skills to remote locations[61,65-67]. Due to the higher travel costs and travel distances to health care facilities, it seems likely that telemedicine will continue to be especially costeffective in rural areas.

Due to ageing populations and corresponding rises in chronic illness $[2,3,13,14]$, the demand for unscheduled health care is likely to continue to rise in developed countries. It is argued [10] that interventions to reduce demand for unplanned care should target socially deprived individuals, but they can be especially difficult to identify in rural areas where overall affluence may mask individual deprivation [32]. This review found that chronic illness management, telemedicine and community health clinics all had potential to reduce use of unplanned health care by rural populations. Future research should evaluate interventions more robustly and more clearly report the results.

\section{Acknowledgements}

Funding came from the North Norfolk Clinical Commissioning Group and the Norfolk and Suffolk Primary and Community Care Research Office (UK).

\section{References}

1. HSCIC (2014) Accident and Emergency Attendances in England - 2012-13, Experimental statistics. Health and Social Care Information Centre.

2. Hirshon JM, Risko N, Calvello EJ, Ramirez SSd, Narayan M, et al. (2013) Health systems and services: the role of acute care. Bulletin of the World Health Organization, 91 (5), 386-388. 
3. Pines JM, Hilton JA, Weber EJ, Alkemade AJ, Al Shabanah H, et al. (2011) International perspectives on emergency department crowding. Academic Emergency Medicine, 18 (12), 1358-1370.

4. Policy Exchange (2012) All Together Now: Competitive integration in the NHS.

5. Nuffield Trust (2013) Focus on preventable admissions: Trends in emergency admissions for ambulatory care sensitive conditions, 2001 to 2013. .

6. HSCIC (2005) Ambulance services, England: 2004-05 Health \& Social Care Information Centre. Bulletin 2005/01/HSCIC Bulletin 2005/01/HSCIC.

7. HSCIC (2013) Ambulance Services, England 2012-13. Health and Social Care Information Centre 1.0 1.0 .

8. Patton GG\& Thakore S (2012) Reducing inappropriate emergency department attendances-a review of ambulance service attendances at a regional teaching hospital in Scotland. Emergency Medicine Journal, emermed-2012-201116.

9. Ismail SA, Gibbons DC\& Gnani S (2013) Reducing inappropriate accident and emergency department attendances: a systematic review of primary care service interventions. British Journal of General Practice, 63 (617), e813-e820.

10. O'Cathain A, Knowles E, Maheswaran R, Pearson T, Turner J, et al. (2013) A system-wide approach to explaining variation in potentially avoidable emergency admissions: national ecological study. BMJ Quality \& Safety, bmjqs-2013.

11. Spence D (2013) Who's to blame for overcrowding in accident and emergency departments? British Medical Journal, 346.

12. Zhou Y, Abel G, Warren F, Roland M, Campbell J, et al. (2014) Do difficulties in accessing in-hours primary care predict higher use of out-of-hours GP services? Evidence from an English National Patient Survey. Emergency Medicine Journal, emermed-2013-203451.

13. Rechel B, Doyle Y, Grundy E\& McKee M (2009) How can health systems respond to population ageing? Policy Brief: World Health Organisation Geneva. pp. 43.

14. The King's Fund (2014) Ageing population. The King's Fund.

15. Regan S\& Wong S (2009) Patient perspectives on primary health care in rural communities: effects of geography on access, continuity and efficiency. Rural and Remote Health 9 (online), 9 (1142).

16. Nelson W, Pomerantz A, Howard K\& Bushy A (2007) A proposed rural healthcare ethics agenda. Journal of Medical Ethics, 33 (3), 136-139.

17. Cancer Research UK (2008) Policy Statement: Rural health inequalities relating to cancer Cancer Research UK.

18. Farmer J, Iversen L, Campbell NC, Guest C, Chesson R, et al. (2006) Rural/urban differences in accounts of patients' initial decisions to consult primary care. Health \& Place, 12 (2), 210-221.

19. Age UK (2013) Later Life in Rural England. London: Age UK.

20. BMA (2005) Healthcare in a Rural Setting. British Medical Assocation: Board of Science.

21. Steinhaeuser J, Otto P, Goetz K, Szecsenyi J\& Joos S (2014) Rural area in a European country from a health care point of view: an adaption of the Rural Ranking Scale. BMC Health Services Research, 14 (1), 147.

22. WHO (2010) Rural poverty and health systems in the WHO European Region. Copenhagen, Denmark: WHO Regional Office for Europe.

23. Rosenblatt RA (2010) Commentary: do medical schools have a responsibility to train physicians to meet the needs of the public? The case of persistent rural physician shortages. Academic Medicine, 85 (4), 572-574.

24. Vanasse A, Courteau J, Cohen A, Orzanco M\& Drouin C (2010) Rural-urban disparities in the management and health issues of chronic diseases in Quebec (Canada) in the early 2000s. Rural and Remote Health, 10 (1058), 1-15.

25. Brundisini F, Giacomini M, DeJean D, Vanstone M, Winsor S, et al. (2013) Chronic Disease Patients' Experiences With Accessing Health Care in Rural and Remote Areas: A Systematic Review and Qualitative Meta-Synthesis. Ontario health technology assessment series, 13 (15), 1. 
26. Winterton R\& Warburton J (2011) Models of care for socially isolated older rural carers: barriers and implications. Rural and Remote Health, 11 (3), 1678.

27. Hartley D (2004) Rural health disparities, population health, and rural culture. American Journal of Public Health, 94 (10), 1675.

28. Smith J (2007) Australia's rural and remote health: A social justice perspective: Pearson Education.

29. European Commission (2008) Poverty and Social Exclusion in rural areas Directorate-General for Employment, Social Affairs and Equal Opportunities Unit E2

30. Smith T, Noble S, Dibben C, Heynat J\& Avenall D (2006) DEPRIVATION IN RURAL NORFOLK: Final Report. Brighton, UK: Oxford Consultants for Social Inclusion. $59 \mathrm{p}$.

31. Bertin M, Chevrier C, Pelé F, Serrano-Chavez T, Cordier S, et al. (2014) Can a deprivation index be used legitimately over both urban and rural areas? International Journal of Health Geographics, 13 (1), 22.

32. Haynes R\& Gale $S(2000)$ Deprivation and poor health in rural areas: inequalities hidden by averages. Health \& Place, 6 (4), 275-285.

33. Riva M, Curtis S, Gauvin L\& Fagg J (2009) Unravelling the extent of inequalities in health across urban and rural areas: evidence from a national sample in England. Social Science \& Medicine, 68 (4), 654-663.

34. Purdey S\& Huntley A (2013) Predicting and preventing avoidable hospital admissions: a review. The Journal of the Royal College of Physicians of Edinburgh, 43 (4), 340-344.

35. NHS England (2013) Understanding the New NHS. pp. 27.

36. Higgins J, Altman DG, Gøtzsche PC, Jüni P, Moher D, et al. (2011) The Cochrane Collaboration's tool for assessing risk of bias in randomised trials. British Medical Journal, 343.

37. Wells G, Shea B, O'connell D, Peterson J, Welch V, et al. (2000) The Newcastle-Ottawa Scale (NOS) for assessing the quality of nonrandomised studies in meta-analyses. http://www.medicine.mcgill.ca/rtamblyn/Readings/The\%20Newcastle\%20-\%20Scale\%20for \%20assessing\%20the\%20quality\%20of\%20nonrandomised\%20studies\%20in\%20metaanalyses.pdf.

38. Rust G, Baltrus P, Ye J, Daniels E, Quarshie A, et al. (2009) Presence of a community health center and uninsured emergency department visit rates in rural counties. The Journal of Rural Health, 25 (1), 8-16.

39. Thaker DA, Monypenny R, Olver I\& Sabesan S (2013) Cost savings from a telemedicine model of care in northern Queensland, Australia. Medical Journal of Australia, 199 (6), 414-417.

40. Sabesan S\& Brennan S (2011) Tele Oncology for Cancer Care in Rural Australia: InTech Open Access Publisher. 289-306 p.

41. Lewis GH, Georghiou T, Steventon A, Vaithianathan R, Chitnis X, et al. (2013) Impact of 'Virtual Wards' on hospital use: a research study using propensity matched controls and a cost analysis. National Institute for Health Research Service Delivery and Organisation Programme. 157 p.

42. Thiel V, Sonola L, Goodwin N\& Kodner DL (2013) Developing community resource teams in Pembrokeshire, Wales Integration of health and social care in progress. The King's Fund. $31 \mathrm{p}$.

43. Rettig BA, Shrauger DG, Recker RR, Gallagher TF\& Wiltse H (1986) A randomized study of the effects of a home diabetes education program. Diabetes Care, 9 (2), 173-178.

44. Dracup K, Moser DK, Pelter MM, Nesbitt T, Southard J, et al. (2014) A Randomized Controlled Trial to Improve Self-Care in Patients with Heart Failure Living in Rural Areas. Circulation, AHA. 113.

45. Stampehl MR, Call CF, Pope SM, Hartwig M\& Jennison S (2012) Rural heart failure management by telemedicine: Lessons learned. Journal of Cardiac Failure, 1), S98.

46. Varma N, Epstein AE, Irimpen A, Schweikert R\& Love C (2010) Efficacy and safety of automatic remote monitoring for implantable cardioverter-defibrillator follow-up the Lumos-T Safely Reduces Routine Office Device Follow-Up (TRUST) trial. Circulation, 122 (4), 325-332.

47. Rasekaba TM, Williams E\& Hsu-Hage B (2009) Can a chronic disease management pulmonary rehabilitation program for COPD reduce acute rural hospital utilization? Chronic Respiratory Disease, 6 (3), 157-163. 
48. Kates N, Crustolo AM, Nikolaou L, Craven MA\& Farrar S (1997) Providing psychiatric backup to family physicians by telephone. Canadian Journal of Psychiatry - Revue Canadienne de Psychiatrie, 42 (9), 955-959.

49. Saurman E, Perkins D, Roberts R, Roberts A, Patfield M, et al. (2011) Responding to mental health emergencies: implementation of an innovative telehealth service in rural and remote new South Wales, Australia. Journal of Emergency Nursing, 37 (5), 453-459.

50. Bradley AC, Baker A\& Lewin TJ (2007) Group intervention for coexisting psychosis and substance use disorders in rural Australia: outcomes over 3 years. Australian \& New Zealand Journal of Psychiatry, 41 (6), 501-508.

51. Crane S, Sailer D\& Patch SC (2011) Improving asthma care in emergency departments: results of a multihospital collaborative quality initiative in rural western North Carolina. North Carolina Medical Journal, 72 (2), 111-117.

52. Postma JM, Smalley K, Ybarra V\& Kieckhefer G (2011) The feasibility and acceptability of a homevisitation, asthma education program in a rural, Latino/a population. Journal of Asthma, 48 (2), 139-146.

53. Valery PC, Masters IB, Taylor B, Laifoo Y, O'Rourke PK, et al. (2010) An education intervention for childhood asthma by Aboriginal and Torres Strait Islander health workers: a randomised controlled trial. Medical Journal of Australia, 192 (10), 574-579.

54. Larson A, Ward J, Ross L, Whyatt D, Weatherston M, et al. (2010) Impact of structured education and self management on rural asthma outcomes. Australian Family Physician, 39 (3), 141.

55. Sonola L, Thiel V, Goodwin N\& Kodner DL (2013) South Devon and Torbay Proactive case management using the community virtual ward and the Devon Predictive Model. The King's Fund. $32 \mathrm{p}$.

56. van den Berg N, Meinke C, Matzke M, Heymann R, Flessa S, et al. (2010) Delegation of GP-home visits to qualified practice assistants: assessment of economic effects in an ambulatory healthcare centre. BMC Health Services Research, 10 (1), 155.

57. Mitton C, O'Neil D, Simpson L, Hoppins Y\& Harcus S (2007) Nurse-Physician Collaborative Partnership: a rural model for the chronically ill. Canadian Journal of Rural Medicine, 12 (4), 208-216.

58. Finkelstein SM, Speedie SM, Zhou X, Potthoff S\& Ratner ER (2011) Perception, satisfaction and utilization of the VALUE home telehealth service. Journal of Telemedicine and Telecare, 17 (6), 288-292.

59. Gruenewald D, Virtue J, Kopf W, Hartmann T, Nason E, et al. (2013) Outcomes for outpatient veterans with cancer receiving care coordination-home telehealth services. Journal of the American Geriatrics Society, 61, S56.

60. Ono Y, Sakai A, Otsuka K, Uda H, Oyama H, et al. (2013) Effectiveness of a Multimodal Community Intervention Program to Prevent Suicide and Suicide Attempts: A Quasi-Experimental Study. PLOS ONE.

61. Saffle JR, Edelman L, Theurer L, Morris SE\& Cochran A (2009) Telemedicine evaluation of acute burns is accurate and cost-effective. Journal of Trauma - Injury, Infection and Critical Care, 67 (2), 358-365.

62. Dellasega CA\& Zerbe TM (2000) A multimethod study of advanced practice nurse postdischarge care. Clinical Excellence for Nurse Practitioners, 4 (5), 286-293.

63. Smith WR, Culley L, Plorde M, Murray JA, Hearne T, et al. (2001) Emergency medical services telephone referral program: an alternative approach to nonurgent 911 calls. Prehospital Emergency Care, 5 (2), 174-180.

64. O'Cathain A, Knowles E, Munro J\& Nicholl J (2007) Exploring the effect of changes to service provision on the use of unscheduled care in England: population surveys. BMC Health Services Research, 7 (1), 61. 
65. Hoechsmann A (2012) Decrease in medevacs and overall transportation to a regional emergency department with implementation of territorial picture archiving and communication system. Canadian Journal of Emergency Medicine, 14, S13.

66. Westbrook JI, Coiera EW, Brear M, Stapleton S, Rob MI, et al. (2008) Impact of an ultrabroadband emergency department telemedicine system on the care of acutely ill patients and clinicians' work. Medical Journal of Australia, 188 (12), 704-708.

67. Armstrong IJ\& Haston WS (1997) Medical decision support for remote general practitioners using telemedicine. Journal of Telemedicine and Telecare, 3 (1), 27-34.

68. Brennan JA, Kealy JA, Gerardi LH, Shih R, Allegra J, et al. (1999) Telemedicine in the emergency department: a randomized controlled trial. Journal of Telemedicine and Telecare, 5 (1), 18-22.

69. Miyasaka K, Suzuki Y, Sakai H\& Kondo Y (1997) Interactive communication in high-technology home care: videophones for pediatric ventilatory care. Pediatrics, 99 (1), E1.

70. Benger JR, Noble SM, Coast J\& Kendall JM (2004) The safety and effectiveness of minor injuries telemedicine. Emergency Medicine Journal, 21 (4), 438-445.

71. Welsh Government (2011) Delivering Rural Health Care Services. ISBN 9780750462150 ISBN 978 $0750462150.38 \mathrm{p}$.

72. Wood J (2004) Rural Health and Healthcare: a North West perspective. Lancaster, UK: Institute for Health Research, Lancaster University. ISBN 1-86220-144-7 ISBN 1-86220-144-7. 84 p.

73. Swindlehurst H, Deaville J, Wynn-Jones J\& Mitchinson K (2005) Rural Proofing for Health: A Commentary. Rural and Remote Health, 5 (411 (Online)).

74. Community Council of Devon (2010) Draft Rural Health \& Wellbeing Strategy for Devon 2010-2013: CCD response. $7 \mathrm{p}$.

75. Farmer J, Munoz S-A, Steinerowski A\& Bradley S (2010) Health, wellbeing and community involvement of older people in rural Scotland. In: Le $Q$, editor. Health and wellbeing: a social and cultural perspective. New York: Nova Science. pp. 128-144.

76. Purdy S, Paranjothy S, Huntley A, Thomas R, Mann M, et al. (2012) Interventions to reduce unplanned hospital admission: a series of systematic reviews. Bristol: University of Bristol. 186 p.

77. Huntley A, Lasserson D, Wye L, Morris R, Checkland K, et al. (2014) Which features of primary care affect unscheduled secondary care use? A systematic review. BMJ Open, 4 (5), e004746.

78. Deeks JJ, Dinnes J, D'amico R, Sowden A, Sakarovitch C, et al. (2003) Evaluating non-randomised intervention studies. Health Technology Assessment, 7 (27), 1-179. 
Table 1. Selected studies in review

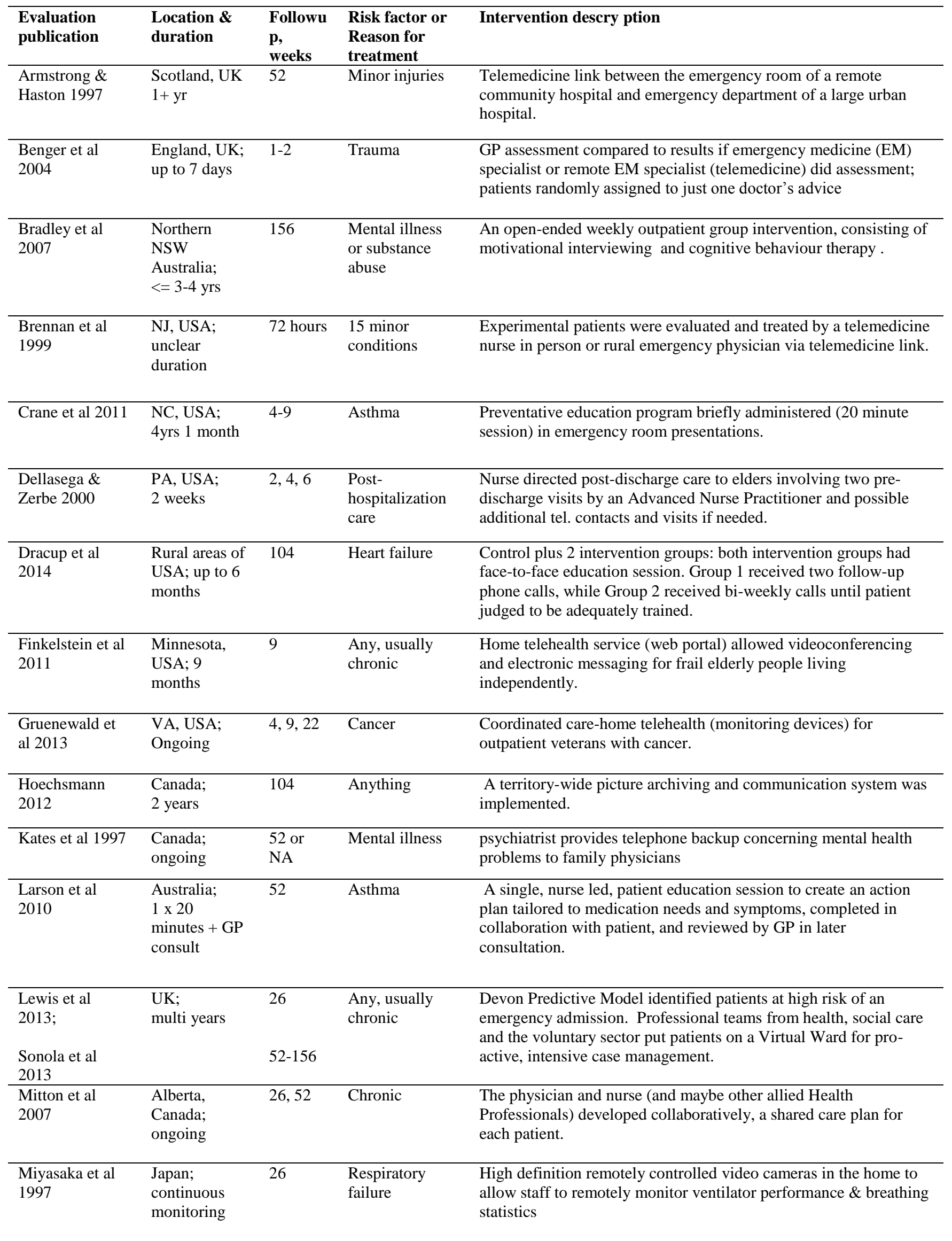




\begin{tabular}{|c|c|c|c|c|}
\hline $\begin{array}{l}\text { O'Cathain et al } \\
2007\end{array}$ & $\begin{array}{l}\text { England, UK; } \\
5 \text { yrs }\end{array}$ & 208 & Anything & $\begin{array}{l}\text { Population surveys used to explore impacts of new services on } \\
\text { demand for traditional providers of unscheduled care. }\end{array}$ \\
\hline $\begin{array}{l}\text { Postma et al } \\
2011\end{array}$ & $\begin{array}{l}\text { WA, USA; } \\
8 \text { sessions in } 8 \\
\text { months }\end{array}$ & $17-52$ & Asthma & $\begin{array}{l}\text { Home-visitation intervention designed to decrease environmental } \\
\text { triggers for pediatric asthma in rural Latino families. }\end{array}$ \\
\hline $\begin{array}{l}\text { Rasekaba et al } \\
2009\end{array}$ & $\begin{array}{l}\text { Kyabram, } \\
\text { Australia; } 3 \text { or } \\
8 \text { weeks }\end{array}$ & 52 & COPD & $\begin{array}{l}\text { Once-weekly, eight-week multidisciplinary Pulmonary } \\
\text { Rehabilitation program as an integral part of the COPD chronic } \\
\text { disease management program }\end{array}$ \\
\hline Rettig et al 1986 & $\begin{array}{l}\text { NE, USA; }<= \\
12 \text { visits in } \\
6 \text { months }\end{array}$ & $26-52$ & Diabetes & $\begin{array}{l}\text { Health nurses provided individualized instruction in diabetes self- } \\
\text { care within the home, }\end{array}$ \\
\hline Rust et al 2009 & $\begin{array}{l}\text { GA, USA; } \\
3 \text { years }\end{array}$ & 156 & Any & $\begin{array}{l}\text { Community health centers subsidized by grants from US Federal } \\
\text { Government under Section } 330 \text {. }\end{array}$ \\
\hline $\begin{array}{l}\text { Sabeson \& } \\
\text { Brennan 2011; } \\
\text { Thaker et al } \\
2011\end{array}$ & $\begin{array}{l}\text { Queens-land, } \\
\text { Australia; } \\
\text { ongoing }\end{array}$ & $\begin{array}{l}\text { survey } \\
\text { over } 52- \\
182 \\
\text { weeks }\end{array}$ & Cancer & $\begin{array}{l}\text { Telemedicine model for cancer care (tele-oncology) in northern } \\
\text { Queensland, Australia, compared with the usual model of care from } \\
\text { the perspective of the Townsville and other participating hospital } \\
\text { and health services }\end{array}$ \\
\hline Saffle et al 2009 & $\begin{array}{l}\text { UT, MT, ID, } \\
\text { USA; } \\
2+\text { yrs }\end{array}$ & $\begin{array}{l}\text { over } \\
104 \\
\text { weeks }\end{array}$ & Burns & $\begin{array}{l}\text { Video consultation with acute burns specialists and remote } \\
\text { hospitals }\end{array}$ \\
\hline $\begin{array}{l}\text { Saurman et al } \\
2011\end{array}$ & $\begin{array}{l}\text { NSW, } \\
\text { Australia, } \\
\text { continuous }\end{array}$ & 78 & $\begin{array}{l}\text { Mental illness } \\
\text { (any) }\end{array}$ & Video assessments of mental health conditions \\
\hline Smith et al 2001 & $\begin{array}{l}\text { WA, USA; } \\
4 \text { months }\end{array}$ & 2 days & Anything & $\begin{array}{l}\text { "Transferring non-urgent } 911 \text { calls to a 24-hour consulting nurse } \\
\text { line rather than sending a basic life support unit" [ambulance] }\end{array}$ \\
\hline $\begin{array}{l}\text { Stampehl et al } \\
2012\end{array}$ & $\begin{array}{l}\text { American } \\
\text { midwest, 7-90 } \\
\text { days }\end{array}$ & 13 & Heart failure & $\begin{array}{l}\text { Telehealth technologies and a heart failure nursing outreach } \\
\text { program. Phone calls and daily symptoms monitored by Cardiocom } \\
\text { telescale for } 90 \text { days. }\end{array}$ \\
\hline Thiel et al 2013 & $\begin{array}{l}\text { Wales UK; } \\
1 \text { yr of data }\end{array}$ & 78 & $\begin{array}{l}\text { Any, usually } \\
\text { chronic }\end{array}$ & $\begin{array}{l}\text { Community resource teams delivering integrated care in homes and } \\
\text { communities. }\end{array}$ \\
\hline $\begin{array}{l}\text { Valery et al } \\
2010\end{array}$ & $\begin{array}{l}\text { Islands of } \\
\text { Australia; } \\
6 \text { months. }\end{array}$ & 52 & Asthma & $\begin{array}{l}67 \text { indigenous peer educators, made minimum three home visits to } \\
\text { promote awareness of asthma management in children. }\end{array}$ \\
\hline $\begin{array}{l}\text { van den Berg et } \\
\text { al } 2010\end{array}$ & $\begin{array}{l}\text { Germany; } \\
2 \text { yrs }\end{array}$ & 104 & Usually Chronic & $\begin{array}{l}\text { Physician assistant rather than General Practitioner sometimes saw } \\
\text { patients in own homes. }\end{array}$ \\
\hline $\begin{array}{l}\text { Varma et al } \\
2010\end{array}$ & $\begin{array}{l}\text { USA; } 12-15 \\
\text { months }\end{array}$ & $13-63$ & Heart failure & $\begin{array}{l}\text { Remote home monitoring of patients with implantable cardiac } \\
\text { electronic devices }\end{array}$ \\
\hline $\begin{array}{l}\text { Westbrook et al } \\
2008\end{array}$ & $\begin{array}{l}\text { South } \\
\text { Australia; } \\
18 \text { months }\end{array}$ & 77 & $\begin{array}{l}\text { Major trauma, } \\
\text { critical care }\end{array}$ & $\begin{array}{l}\text { Before-and-after study of use of ultra-broadband connection } \\
\text { allowing real-time audio-visual communication between clinicians } \\
\text { at distant sites. }\end{array}$ \\
\hline
\end{tabular}


Table 2. Interventions that had statistically significant reductions in unplanned care use.

\begin{tabular}{|c|c|c|c|}
\hline Population and setting & Study design (n) & Intervention summary & Statistically significant results \\
\hline $\begin{array}{l}\text { Frail elderly people in } \\
\text { rural Minnesota, USA }\end{array}$ & $\begin{array}{l}\text { Randomised controlled trial. } \\
44 \text { patients intervention, } \\
40 \text { pt controls }\end{array}$ & $\begin{array}{l}\text { Home telehealth service } \\
\text { for frail elderly living in } \\
\text { community [58] }\end{array}$ & $\begin{array}{l}\text { Based on weekly interviews (so self-reported) and compared to } 40 \text { control subjects, } 44 \text { intervention participants } \\
\text { made fewer emergency department visits ( } 5 \text { vs. } 17, \mathrm{p} \text { value for difference }=0.015 \text { ), had fewer visits in all } \\
\text { categories of home care utilization ( } 12 \text { vs. } 50 ; \mathrm{p}<=0.05 \text { ), and lower use of transportation services }(15 \mathrm{vs.} 26, \mathrm{p}= \\
0.017 \text { ). }\end{array}$ \\
\hline $\begin{array}{l}\text { Children on home } \\
\text { ventilators in Japan }\end{array}$ & $\begin{array}{l}10 \text { patients, observed before and } \\
\text { after equipment installation }\end{array}$ & $\begin{array}{l}\text { Tele-monitoring of } \\
\text { children on home } \\
\text { ventilators [69] }\end{array}$ & $\begin{array}{l}\text { In a group of } 10 \text { patients over } 6 \text { months before and after equipment installation, there were } 24 \text { unscheduled } \\
\text { hospital visits before, and } 5 \text { visits after installation of equipment }(p<0.01) \text {. }\end{array}$ \\
\hline $\begin{array}{l}\text { Rural population of in } \\
\text { Japan }\end{array}$ & $\begin{array}{l}\text { Rates observed before and after } \\
\text { implementation of multimodal } \\
\text { intervention ( } 631,133 \text { participants) }\end{array}$ & $\begin{array}{l}\text { Suicide prevention } \\
\text { program [60] }\end{array}$ & $\begin{array}{l}\text { Rate of suicides in the intervention group decreased } 7 \% \text { compared with that of the control group. Subgroup } \\
\text { analyses demonstrated suicide rate in the intervention group was significantly lower in males }(\mathrm{RR}=0.77,95 \% \\
\text { CI } 0.59-0.998, \mathrm{p}=0.0485) \text { and the number of suicide attempts was significantly lower in males (Rate Ratio = } \\
0.39,95 \% \text { CI } 0.22-0.68, p=0.001) \text { and the elderly }(\mathrm{RR}=0.35,95 \% \text { CI } 0.17-0.71, \mathrm{p}=0.004) \text {. }\end{array}$ \\
\hline $\begin{array}{l}\text { Children of migrant } \\
\text { agricultural labourers, } \\
\text { rural USA }\end{array}$ & $\begin{array}{l}866 \text { patients, before and after } \\
\text { receipt of asthma management } \\
\text { education }\end{array}$ & $\begin{array}{l}\text { Asthma self- } \\
\text { management [52] }\end{array}$ & $\begin{array}{l}\text { Average number of emergency hospital admissions in } 12 \text { months before intervention }=0.46 \text { per participant, } \\
\text { falling to } 0.22 \text { in } 12 \text { months after intervention (decline }>50 \% ; p<0.005 \text { ). }\end{array}$ \\
\hline $\begin{array}{l}\text { Small town in rural area } \\
\text { of Australia }\end{array}$ & $\begin{array}{l}\text { Concurrent comparisons of } 29 \\
\text { patients in intervention programme } \\
\text { compared to } 24 \text { in opt-out cohort }\end{array}$ & $\begin{array}{l}\text { COPD self-management } \\
\text { [47] }\end{array}$ & $\begin{array}{l}\text { Significant reductions in cumulative acute hospital care utilization indicators }(95 \% \text { emergency department } \\
\text { presentations, } 95 \% \text { inpatient admissions, } 99 \% \text { length of stay; effect sizes }=0.62-0.66, p<0.001) 12 \text { months after } \\
\text { the introduction of the program; in contrast, changes in the cumulative indicators were statistically insignificant } \\
\text { for the non-intervention cohort (emergency department presentations decreased by } 5 \% \text {, inpatient admissions } \\
\text { decreased by } 12 \% \text {, length of stay increased by } 30 \% \text {; effect size }=0.14-0.40, P>0.05) \text {. }\end{array}$ \\
\hline $\begin{array}{l}\text { All population in rural } \\
\text { counties of Georgia, } \\
\text { USA }\end{array}$ & $\begin{array}{l}\text { Concurrent visit rates from counties } \\
\text { with accessible primary clinics } \\
\text { (population total }=215,559 \text { ) } \\
\text { compared to visit rates from } \\
\text { counties without such clinics } \\
\text { (population total }=1,351,919 \text { ). }\end{array}$ & $\begin{array}{l}\text { Community health } \\
\text { centres (CHCs) for } \\
\text { primary care in poor } \\
\text { communities [38] }\end{array}$ & $\begin{array}{l}\text { Counties without a CHC had 33\% higher rates of uninsured all-cause Emergency Department (ED) visits per } \\
10,000 \text { uninsured population. Compared with non-CHC counties (rate ratio=1.33, 95\% CI=1.11-1.59). Higher } \\
\text { ED visit rates remained significant ( } R R=1.21,95 \% \mathrm{CI}=1.02-1.42 \text { ) after adjustment for percent of population } \\
\text { below poverty level, percent black, and number of hospitals. Uninsured ED visit rates were also higher for } \\
\text { various categories of diagnoses, but remained statistically significant on multivariate analysis only for } \\
\text { ambulatory care sensitive conditions (adjusted } \mathrm{RR}=1.22,95 \% \mathrm{CI}=1.01-1.47 \text { ). No such relationship was found } \\
\text { for ED visit rates of insured patients ( } \mathrm{RR}=1.06,95 \% \mathrm{CI}=0.92-1.22) \text {. }\end{array}$ \\
\hline $\begin{array}{l}\text { Rocky mountains area } \\
\text { of USA }\end{array}$ & $\begin{array}{l}\text { Before and after count of } \\
\text { emergency air transport events }\end{array}$ & $\begin{array}{l}\text { Acute burns } \\
\text { telemedicine assessment } \\
\text { and advice [61] }\end{array}$ & $\begin{array}{l}\text { Only } 31 \text { patients (of } 70 \text { presentations) seen by telemedicine received emergency air transport ( } 44.3 \% \text { of total, in } \\
25 \text { month period after program was introduced), compared with } 100 \% \text { of } 29 \text { patients who presented in the } 25 \\
\text { months before the program was implemented }(\mathrm{p}<0.05) \text {. }\end{array}$ \\
\hline Rural Australia & $\begin{array}{l}\text { Before and after patterns of use and } \\
\text { measures of aspects of care. } \mathrm{N}=169 \\
\text { patients in } 12 \text { months before, and } \\
\mathrm{n}=181 \text { patients in } 18 \text { months after. }\end{array}$ & $\begin{array}{l}\text { Telemedicine to assess } \\
\text { and possibly treat } \\
\text { suspected major trauma } \\
{[66]}\end{array}$ & $\begin{array}{l}\text { For critical care patients, admissions fell significantly ( } 54 \% \text { to } 30 \% ; \mathrm{p}=0.01) \text {, transfers increased ( } 21 \% \text { to } 39 \% \text {; } \\
\mathrm{p}=0.01 \text { ), and more procedures were performed. For moderate trauma patients, discharges increased } \\
\text { significantly ( } 45 \% \text { to } 63 \% ; \mathrm{p}=0.039) \text {, and transfers decreased ( } 48 \% \text { to } 25 \% ; \mathrm{p}=0.01 \text { ). }\end{array}$ \\
\hline
\end{tabular}

